\title{
Metabolic syndrome is independently associated with microalbuminuria in type 2 diabetes
}

\author{
Alireza Esteghamati - Armin Rashidi • \\ Omid Khalilzadeh · Haleh Ashraf · Mehrshad Abbasi
}

Published online: 26 August 2009

(C) Springer-Verlag 2009

Erratum to: Acta Diabetol

DOI 10.1007/s00592-009-0131-6

Owing to an error in typesetting, the third author's name was rendered incorrectly. The correct spelling is given here.

The online version of the original article can be found under doi:10.1007/s00592-009-0131-6.

A. Esteghamati $(\bowtie) \cdot$ A. Rashidi · O. Khalilzadeh .

H. Ashraf · M. Abbasi

Endocrinology and Metabolism Research Center (EMRC),

Vali-Asr Hospital, Tehran University of Medical Sciences,

P.O. Box 13145-784, Tehran, Iran

e-mail: esteghamati@tums.ac.ir 